\title{
The Stage View and Temporary Intrinsics*
}

THEOdore Sider $\quad$ Analysis 60 (2000): 84-88

Four-dimensionalism, as I'll use the term, is the doctrine that reality is spread out in time as well as space. ${ }^{1}$ Just as objects that are located at multiple regions of space contain parts confined to those regions of space, so objects that are located at multiple regions of time contain parts - temporal parts - that are confined to those regions of time. (Or better: an object that occupies an extended spatiotemporal region $\mathrm{R}$ has parts confined to the various subregions of R; but I'll ignore this complication henceforth.)

Most who accept this ontology of perduring objects, as they are often called, identify the continuants of our everyday ontology with "space-time worms" - mereological sums of stages from different times. Elsewhere (I996) I have proposed a different version of four-dimensionalism, which identifies continuants with the stages themselves, and which analyses de re temporal predication with a temporal version of modal counterpart theory (Lewis, I968, r97 I). On this view, a current assertion of 'Clinton was indiscreet' is true iff the (current) referent of 'Clinton' - a stage - has an indiscreet temporal counterpart in the past. The temporal counterpart relation is the same "genidentity" or "unity" relation used by the worm theorist to unify the successive stages of continuing space-time worms. In my 1996 I supported this view by appeal to its ability to resolve various philosophical puzzles, including the paradoxes of material constitution and Derek Parfit's (I97I) puzzle about identity and what matters; the purpose of the present note is to mention one other line of argument.

A widely discussed contemporary argument for temporal parts is David Lewis's argument from temporary intrinsics, according to which only the fourdimensionalist can explain the phenomenon of intrinsic change. ${ }^{2} \mathrm{I}$ am now straight-shaped, but will fail to be straight-shaped in the future. There is an

*Thanks to Tamar Szabó Gendler, Hud Hudson, Ned Markosian, and Trenton Merricks for helpful comments.

${ }^{1}$ See my 1997 for a more careful exposition of four-dimensionalism. This terminology is not perfect: 'four-dimensionalism' is also sometimes used for the view in the philosophy of time called "eternalism", on which past, present and future are equally real. According to some, four-dimensionalism presupposes eternalism (see Merricks (1995)). I argue against this claim in my forthcoming book Four-Dimensionalism, but here I set this issue aside.

${ }^{2}$ The argument is in Lewis (1986, 202-204). For discussion see Forbes (1987); Haslanger (1989); Hawley (1998); Hinchliff (I996); Johnston (1987); Lewis (1988); Lowe (I987, I988); Merricks (I994); Zimmerman (I998). 
apparent contradiction — that I both am, and am not, straight-shaped — that must be resolved in some way. How? Lewis distinguishes three solutions. i) The apparent contradiction is resolved by saying that straightness is actually a relation: I am straight $a t$, or with respect to, one time, but not at (or with respect to) another. But this seems to conflict with the fact that straightness is an intrinsic property: straightness-with-respect-to-t seems no more intrinsic than being taller than Bill Clinton. ii) The apparent contradiction arises from a mistaken philosophy of time. The argument assumes that both my present straightness and my future lack of straightness are equally real. But presentism, the doctrine that only the present is real, is true. Thus, I am just plain straight; and it is just plain false that I am not straight. I do have various tensed properties, such as the property of futurely being not straight. But this is no more a lack of straightness than is being possibly not straight. The solution is nice, but comes at the price of accepting presentism, a price many do not wish to pay. ${ }^{3}$ iii) The apparent contradiction is resolved by claiming that the incompatible intrinsic properties, being straight and being not straight are had by distinct temporal parts of a single space-time worm. This is Lewis's favored solution. But (unlike the first two solutions) it presupposes temporal parts. Thus Lewis's argument for temporal parts is that they are required by the best solution to the problem of temporary intrinsics.

There has been much written on various aspects of this argument; I want to comment on just one aspect of that literature, a certain rejoinder to Lewis that has been advanced in various places. ${ }^{4}$ According to Lewis, I am a sum of stages, some of which are straight-shaped, others of which are not. I, therefore, cannot be said to be straight-shaped simpliciter. Rather, I am straight-shaped at the present time, derivatively, since my current temporal part is straight-shaped simpliciter. The rejection of solution i) is therefore a delicate matter for Lewis, given that both Lewis and the proponent of solution i) accept that ordinary continuants do not have shapes simpliciter, but only have shapes with respect to times. Here is what Lewis says:

What distinguishes the first solution from the third is not that the third

\footnotetext{
${ }^{3}$ Lewis's original reason for rejecting presentism was not especially compelling (see Zimmerman (1998)); and certain standard objections to presentism can be answered (see my forthcoming "Presentism and Ontological Commitment"), but there are other serious worries about presentism, for example that presentism violates the thesis that truth supervenes on being (Lewis, I 992, p. 2 I9), and that presentism seems inconsistent with special relativity (Putnam, I967).

${ }^{4}$ Haslanger (I989, I I9-I 20); Hinchliff (1996, pp. I 20-I 2 I); Lowe (ı988, pp. 73-74).
} 
does away with shape-at-a-time relations. Rather, it is that the first has wrongly done away with shapes as intrinsic properties that can be had simpliciter. (I988, p. 66)

Thus, Lewis's claim, against solution i), is that it is inconsistent with the alleged fact that some things are straight-shaped simpliciter. These things are not ordinary continuants, but are rather the temporal parts of continuants. But it is here that his opponents have seen a weakness. Even admitting that there is something counterintuitive to solutions i) and ii), Lewis's preferred solution iii) has its own counterintuitive consequence: it violates a plausible principle about change, that an object that changes shape must itself have a shape simpliciter. As Hinchliff (1996, p. I 20) puts it, in discussion of a changing candle, "If the candle never has the shapes itself, it cannot change its shape."

Anyone familiar with this sort of metaphysical debate is familiar with a sort of stalemate one often reaches: we are left with several competing views, each of which is internally consistent, each of which has some intuitively implausible feature or consequence; the question is which consequence we want to swallow. When such a stalemate is reached, it is the end of the role of argumentation, but not the end of the role of reason. Good judgment is called for.

In light of the existence of the stage view, however, stalemate in the debate over temporary intrinsics has not yet been reached. The rejoinder to Lewis only applies to the worm view, not to the stage view. According to the stage view, I myself have the property being straight, for I am a stage, not a space-time worm. The version of four-dimensionalism that emerges the strongest from the problem of temporary intrinsics, then, is not the worm view but rather the stage view, for unlike the worm view, the stage view allows both that temporary intrinsics are instantiated simpliciter, and that they are instantiated by ordinary continuants such as persons and candles.

"Out of the frying pan and into the fire!", many will say: instantiation simpliciter has been purchased at the expense of denying change, for if "continuants" are instantaneous stages then they cannot genuinely persist and so cannot genuinely change. But on the stage view, continuants $d o$ persist and change: I myself, a stage, am straight-shaped, but will be bent-shaped tomorrow. ${ }^{5}$ That is, I have the temporal property futurely being bent, by virtue of

\footnotetext{
${ }^{5}$ It may be objected that the following "tensed schema" does not secure change (where F and $\mathrm{G}$ stand for incompatible intrinsic properties):

A has F, and A will fail to have $\mathrm{G}$ since it attributes a different relation to $A$ and $F$ (instantiation) from that attributed to $A$ and $G$
} 
having a temporal counterpart tomorrow that is bent.

The objector may persist in complaining that stage-theoretic persistence is not genuine persistence. This is the temporal analog of Kripke's (I972, p. 45) "Humphrey objection" to modal counterpart theory; my response (given in more detail in my 1996) parallels responses made to Kripke by Lewis (I986, p. I96) and Hazen (1979). First, it must be stressed that although the analysis of the instantiation of a temporal property by a stage $S$ involves stages other than $S, S$ itself has the temporal property. I myself will be bent. Second, the stage-theoretic analysis of this state of affairs may be controversial, but it is consistent with the basic data of persistence and change, and must be evaluated on the basis of total theory. On that basis, as I argue in my 1996, the stage view is favored over rival accounts.

The stage view, then, is consistent with intrinsic change, but also allows that continuants instantiate shapes and other temporary intrinsics simpliciter. ${ }^{6}$ Note that the presentist solution allows both of these claims as well. This virtue must be weighed against presentism's vices. Solution one, as well, has various virtues and vices, as does Lewis's solution three, the worm view. And of course the same is true of the stage view. A stalemate will eventually be reached. But it is not the same stalemate. To whatever extent the problem of temporary intrinsics is an important consideration, the balance of reasons may be shifted towards the stage view. Whether this is indeed so is a judgment call.

\section{References}

Forbes, Graeme (1987). "Is There a Problem about Persistence?" Aristotelian Society, Supplementary Volume 6r: 137-55. Reprinted in Haslanger and Kurtz 2006: $267-84$.

Haslanger, Sally (1989). "Endurance and Temporary Intrinsics." Analysis 49: I I9-25.

Haslanger, Sally and Roxanne Marie Kurtz (eds.) (2006). Persistence: Contemporary Readings. Cambridge, MA: MIT Press.

(future instantiation), whereas genuine change requires that $A$ have the very same relation to $F$ as to $\mathrm{G}$. But no view could satisfy this desideratum, for if $\mathrm{F}$ and $\mathrm{G}$ are incompatible, nothing can bear the same instantiation relation to both. Once this unattainable standard is set aside, the tensed schema seems reasonable.

${ }^{6}$ The claim that objects have shapes (plural) must be read carefully. According to both presentism and the stage view, any current continuant has only one shape, but will have others. 
Hawley, Katherine (1998). "Why Temporary Properties Are Not Relations between Physical Objects and Times." Proceedings of the Aristotelian Society 98: 2 I I-I6.

Hazen, Allen (1979). "Counterpart-Theoretic Semantics for Modal Logic." Fournal of Philosophy 76: 319-38.

Hinchliff, Mark (1996). “The Puzzle of Change.” In James Tomberlin (ed.), Philosophical Perspectives, volume ı, I 19-36. Cambridge, MA: Blackwell. Reprinted in Haslanger and Kurtz 2006: 287-306.

Johnston, Mark (1987). "Is There a Problem about Persistence?" Aristotelian Society, Supplementary Volume 61: 107-35. Reprinted in Haslanger and Kurtz 2006: 24I-66.

Kripke, Saul (1972). "Naming and Necessity." In Donald Davidson and Gilbert Harman (eds.), Semantics of Natural Language, 253-355, 763-9. Dordrecht: D. Reidel. Revised edition published in 1980 as Naming and Necessity (Harvard University Press, Cambridge, MA).

Lewis, David (1968). "Counterpart Theory and Quantified Modal Logic." Fournal of Philosophy 65: 1 1 3-26. Reprinted in Lewis 1983: 26-46.

- (1971). "Counterparts of Persons and their Bodies." Fournal of Philosophy 68: 203-II. Reprinted in Lewis I983:26-46.

— (I983). Philosophical Papers, Volume I. Oxford: Oxford University Press.

- (I986). On the Plurality of Worlds. Oxford: Blackwell.

- (1988). "Rearrangement of Particles: Reply to Lowe." Analysis 48: 65-72.

- (1992). "Armstrong on Combinatorial Possibility." Australasian fournal of Philosophy 70: 2 I I-24. Reprinted in Lewis 1999: I96-2 I4.

- (I 999). Papers in Metaphysics and Epistemology. Cambridge: Cambridge University Press.

Lowe, E. J. (1987). "Lewis on Perdurance Versus Endurance." Analysis 47: I $5^{2-54}$. 
- (1988). "The Problems of Intrinsic Change: Rejoinder to Lewis." Analysis 48: $72-77$.

Merricks, Trenton (1994). "Endurance and Indiscernibility." Fournal of Philosophy 91: $165-84$.

— (1995). "On the Incompatibility of Enduring and Perduring Entities." Mind IO4: 523-3I.

Parfit, Derek (1971). "Personal Identity." Philosophical Review 80: 3-27. Reprinted in Perry 1975: 199-223.

Perry, John (ed.) (1975). Personal Identity. Berkeley: University of California Press.

Putnam, Hilary (1967). "Time and Physical Geometry." Fournal of Philosophy 64: 240-47.

Sider, Theodore (1996). "All the World's a Stage." Australasian fournal of Philosophy 74: 433-53. Reprinted in Haslanger and Kurtz 2006: 9I-I I 7.

- (1997). "Four-Dimensionalism.” Philosophical Review ro6: I97-23 I. Reprinted in Haslanger and Kurtz 2006: 55-87.

- (1999). "Presentism and Ontological Commitment." Fournal of Philosophy 96: 325-47. Reprinted in Haslanger and Kurtz 2006: $367-9$ I.

- (2001). Four-Dimensionalism. Oxford: Clarendon Press.

Zimmerman, Dean W. (1998). “Temporary Intrinsics and Presentism.” In Dean W. Zimmerman and Peter van Inwagen (eds.), Metaphysics: The Big Questions, 206-19. Cambridge, MA: Blackwell. Reprinted in Haslanger and Kurtz 2006: 393-424. 